\title{
BIBLIOTECONOMIA, FILOSOFIA DA INFORMAÇÃO E EPISTEMOLOGIA SOCIAL. NOTAS PARA UMA POSSÍVEL DISCUSSÃO ENTRE FLORIDI E HABERMAS
}

\author{
Antonio Saturnino Braga *
}

\begin{abstract}
RESUMO
Em dois artigos dedicados à discussão dos fundamentos conceituais da biblioteconomia, Luciano Floridi distingue três possíveis sentidos da noção de epistemologia social: sociologia do conhecimento (de caráter descritivo), abordagem clássica da teoria filosófica do conhecimento social (entendido como conhecimento que envolve relações epistêmicas entre diversos indivíduos), e abordagem revolucionária (construtivista) deste último tipo de teoria. Floridi procura demonstrar que tanto a sociologia do conhecimento quanto as teorias filosóficas do conhecimento são inadequadas para o papel de fundamento conceitual da biblioteconomia, defendendo a tese de que este papel deve ser ocupado por uma "filosofia da informação". O objetivo central deste trabalho consiste em mostrar que o argumento de Floridi a respeito do caráter prescritivo da teoria filosófica do conhecimento pode ser adequadamente respondido por uma interpretação habermasiana da abordagem construtivista deste tipo de teoria.
\end{abstract}

Palavras-chave: Filosofia e biblioteconomia. Epistemologia social. Floridi. Habermas.

\begin{abstract}
In two papers dedicated to the discussion of the conceptual foundation for library science, Luciano Floridi distinguishes three possible meanings of the concept of social epistemology: sociology of knowledge (of descriptive nature), classic approach to the philosophical theory of social knowledge (defined as knowledge which involves epistemic relations between many
\end{abstract}

\footnotetext{
* Doutor em Filosofia pela Universidade Federal do Rio de Janeiro (UFRJ). Professor de Filosofia no Departamento de Administração da Universidade Federal do Rio de Janeiro (UFRJ) e no Programa de Pós-Graduação em Lógica e Metafísica (PPGLM) da UFRJ. E-mail: antoniofsbraga@uol.com.br
} 
individuals) and revolutionary (constructivist) approach to this last kind of theory. Floridi seeks to demonstrate that neither the sociology of knowledge nor the philosophical theories of knowledge are adequate for the role of conceptual foundation of library science, defending the thesis that this role should be played by a "philosophy of information". The essential aim of this paper is to show that Floridi's argument concerning the prescriptive character of the philosophical theory of knowledge can be adequately answered by a habermasian interpretation of the constructivist approach to this kind of theory.

Keywords: Philosophy and library science. Social epistemology. Floridi. Habermas.

\section{Introdução}

Em artigos publicados em 2002 e 2004, Luciano Floridi defende a tese de que a epistemologia social não constitui uma abordagem adequada para a discussão dos fundamentos conceituais da biblioteconomia ${ }^{1}$. Sua proposta é desenvolver uma "Filosofia da Informação" independente, de caráter mais metafísico do que estritamente epistemológico, no quadro da qual a biblioteconomia apareceria como "filosofia da informação aplicada". Os textos de Floridi deixam claro que, ao opor-se à epistemologia social, seu objetivo não é negar a dimensão social da informação, mas negar que essa dimensão possa ser adequadamente analisada no âmbito da epistemologia, tomada como uma teoria filosófica do conhecimento, ou seja, uma teoria de caráter prescritivo. Se a filosofia da informação visada por Floridi é antes de tudo uma metafísica da informação, ou seja, uma teoria geral da realidade baseada na noção de informação, ela, por outro lado, transforma a "filosofia do conhecimento" (epistemologia) num quadro de análise inadequado à ciência da informação.

\footnotetext{
${ }^{1}$ Floridi usa o termo Library and Information Science e a sigla(LIS), ou seja, Biblioteconomia e Ciência da Informação (BCI). Em princípio, a ciência da informação inclui, além da biblioteconomia, a museologia e a arquivologia, assim como análises das estruturas e processos sociais subjacentes ao uso das tecnologias da comunicação e informação nas sociedades contemporâneas. Os argumentos de Floridi deixam claro que, ao defender a tese de que a ciência da informação deve ser vista como "filosofia da informação aplicada", ele pensa, sobretudo, na biblioteconomia. Assim, nossa discussão girará em torno das relações entre filosofia e biblioteconomia - estendendo-se, eventualmente, para a museologia.
} 
Opresente trabalhotem dois objetivos. Numa primeira etapa, apontar certos problemas internos à proposta de Floridi, relacionando os artigos mencionados a outros textos do mesmo autor, de caráter mais abrangente, orientados mais para o esclarecimento das noções deinformação e filosofia da informação do que para a aplicação das mesmas na área da biblioteconomia (FLORIDI, 2003; 2005). Na parte mais substantiva do trabalho, tentaremos mostrar que os ataques de Floridi ao enquadramento epistemológico das ciências da informação podem ser respondidos por meio de uma interpretação habermasiana do conceito genérico de epistemologia social.

\section{O argumento de Floridi}

O objetivo de Floridi é demonstrar que a epistemologia social não é capaz de fornecer fundamentos conceituais adequados à biblioteconomia. Ele inicia seu argumento apresentando uma distinção entre dois campos de pesquisa que podem ser designados pelo termo "epistemologia social". Por um lado, o termo pode referir-se à sociologia do conhecimento, definida como "um estudo descritivo e empírico das causas e condições históricas do (daquilo que normalmente se considera como) conhecimento"; por outro lado, ele pode referir-se à "epistemologia do conhecimento social", definida como "um estudo crítico e conceitual da dimensão social (envolvendo múltiplos agentes) do conhecimento" (FLORIDI, 2002, p. 39). Para Floridi, e nesse ponto seu juízo nos parece acertado, a biblioteconomia possui dimensões normativas, ela envolve discussões e posicionamentos sobre necessidades e valores, sobre aquilo que a sociedade deve buscar ou promover. Em outras palavras, a biblioteconomia exige considerações e análises que vão além do plano puramente descritivo. Isto significa que, do ponto de vista de sua fundamentação conceitual, ela não pode ser vinculada à sociologia do conhecimento, uma vez que esta última atém-se, justamente, à perspectiva descritiva de análise. Restaria a possibilidade de ela vincularse à epistemologia do conhecimento social. Antecipando o argumento que será detalhado a seguir, Floridi pensa que esta última tampouco é adequada, em virtude de um prescritivismo epistemológico demasiado forte. Para Floridi, este tipo de prescritivismo está em descompasso com o 
posicionamento normativo exigido pela biblioteconomia. A alternativa que ele oferece é a filosofia da informação.

Depois de descartar a sociologia da ciência, Floridi procede a uma nova distinção conceitual, desta vez entre duas abordagens da epistemologia do conhecimento social, a "clássica" e a "revolucionária" (FLORIDI, 2002, p. 40). Ele afirma que a abordagem clássica "ainda é veritacional (veritistic); seu objetivo último ainda é a descoberta e justificação da verdade". A abordagem revolucionária, em contrapartida, "argumenta que conhecimento, verdade e justificação são construções sociais". Parece ser possível e interessante identificar esta distinção à conhecida distinção entre abordagens epistemológicas grosso modo realistas ou objetivistas e, por outro lado, abordagens grosso modo pragmáticas, intersubjetivistas, construtivistas, ou "pós-positivistas". De acordo com essa proposta, a abordagem clássica mantém as concepções mais tradicionais de verdade e justificação, de caráter grosso modo realista e correspondentista (como veremos mais à frente, nas versões contemporâneas a correspondência à realidade objetiva é aferida segundo o critério da uniformidade no uso dos predicados em enunciados observacionais elementares). Ela só se associa à noção de "conhecimento social" pelo fato de substituir o enquadramento estático da inteligência individual e do investigador isolado por um enquadramento mais dinâmico, baseado num esforço investigativo distribuído entre múltiplos agentes com variadas interações epistêmicas, abrangendo fenômenos como testemunho, autoridades cognitivas, fontes de conhecimento, e outros deste tipo. A abordagem clássica da epistemologia do conhecimento social assume como tarefa fundamental identificar e analisar critérios para a credibilidade epistêmica destes fatores "sociais" (envolvendo interações epistêmicas entre múltiplos agentes) da produção do conhecimento objetivo (GOLDMAN, 2006). Por estar preocupada com a credibilidade epistêmica, e não com a influência social facticamente exercida, trata-se de uma abordagem de caráter normativo ou filosófico, distinta da sociologia da ciência.

A abordagem revolucionária ou pós-positivista, por outro lado, abandona a concepção grosso modo realista e correspondentista do conhecimento e da verdade, apresentando-os como construções sociais, 
com critérios de justificação essencialmente intersubjetivos. Numa abordagem construtivista do conhecimento e da verdade, critérios de justificação equivalem a critérios de validação intersubjetiva ou social dos enunciados em geral - lembrando que se trata aqui de uma abordagem com pretensões normativas, ou seja, uma abordagem que, longe de reduzir as condições de validade dos conhecimentos a condições sociais facticamente vigentes, especialmente condições de poder e influência social, pretende apresentá-las como condições de validação racional. Voltaremos mais à frente às características e nuanças desta abordagem.

Floridi afirma que, apesar das diferenças, ambas as abordagens são epistemologicamente prescritivas, ou seja, estão orientadas para a determinação daquilo em que as pessoas devem crer, equivalendo àquilo que elas estão justificadas a crer. Concordando em parte com este diagnóstico, gostaríamos, entretanto, de nuançá-lo, abrindo espaço para uma visão mais diversificada do caráter epistemologicamente prescritivo da teoria filosófica do conhecimento. Para tanto, tentaremos explorar mais a distinção entre as abordagens que Floridi chama de "clássica" e "revolucionária", indo além das caracterizações relativamente superficiais do filósofo italiano. A nosso ver, Floridi dá pouca atenção à diferença entre objetivismo e construtivismo na teoria (filosófica) do conhecimento, e isso impede uma visão mais nuançada de seu caráter prescritivo.

Para Floridi, o caráter essencialmente prescritivo da epistemologia social (incluindo as duas abordagens que ele discrimina) gera uma incompatibilidade com a biblioteconomia. Para ele, em outras palavras, embora a biblioteconomia envolva dimensões normativas, ela não admite um fundamento teórico de caráter epistemologicamente prescritivo. Isto se dá pela seguinte razão: a biblioteconomia não lida tanto com a justificação de conhecimentos, nem com conhecimentos devidamente justificados, mas, antes, com necessidades e valores referidos ao acesso às mais variadas fontes de informação, aos mais variados conteúdos para um possível conhecimento, incluindo fontes e conteúdos que seriam inválidos do ponto de vista epistemologicamente prescritivo. O argumento de Floridi encontra-se resumido na seguinte passagem: 
Epistemologia Social e Ciência da Informação não fazem um casamento feliz porque a Ciência da Informação trabalha em um nível mais fundamental do que a epistemologia. Seu objeto não é o próprio conhecimento, mas as fontes de informação que tornam o conhecimento possível, ainda que apenas indiretamente (FLORIDI, 2002, p. 41).

O artigo de 2004 apresenta um argumento equivalente ${ }^{2}$.

Dois pontos precisam de esclarecimento aqui. Primeiro, conteúdo é uma condição necessária para o conhecimento, mas não é a única. Conhecimento significa algo muito preciso em epistemologia: é um conteúdo que seja ao menos verdadeiro (epistemólogos falam de crenças verdadeiras) e possivelmente justificado, isto é, apoiado por boas razões. A análise do conhecimento como crença verdadeira e justificada não é satisfatória, mas isso não é razão para pensar que possamos dispensar a condição da verdade. Falar de "falso conhecimento" não faz sentido. Exatamente como falar de "solteirões casados". Ninguém pode conhecer a Terra como plana, pelo simples fato de que ela não é. Mas, apesar disso, as bibliotecas estão cheias de "falso conhecimento". Portanto, falar da BCI [Biblioteconomia e Ciência da Informação] como uma disciplina preocupada com o conhecimento, ao invés de conteúdo, é ao menos impreciso, e na pior das hipóteses incorreto. BCI lida com conteúdos entendidos como dados significativos (FLORIDI, 2010, p. 42-43).

A conclusão que Floridi tira desses argumentos, exposta de maneira mais clara no artigo de 2002, é a seguinte. Epistemologia Social e Ciência da Informação têm um fundamento comum, mais básico do que a "filosofia do conhecimento", e menos carregado conceitualmente do que esta última, a saber, a "filosofia da informação". Sua proposta parece ser a seguinte. Antes de ser tratada no nível da teoria filosófica do conhecimento, a informação deve ser tratada num nível metafísico,

\footnotetext{
${ }^{2}$ Utilizamos a tradução brasileira de Solange Mostafa e Denise Nova Cruz, publicada em 2010 .
} 
entendido no sentido de uma física especulativa, ou de uma teoria geral da realidade. Nesse nível metafísico, a informação deve ser definida como uma entidade essencialmente relacional, constituída pela relação entre um dado ("falta de uniformidade", "diferença") e um agente capaz de usar este dado (FLORIDI, 2005). Embora o tema exija uma investigação muito mais aprofundada e detalhada, talvez seja possível aproximar as ideias de Floridi daquelas que Edgar Morin apresentou no primeiro volume de sua obra $O$ método. Desse ponto de vista, a informação seria uma possível falta de uniformidade para (que só existe como "para") um possível sistema autopoiético. A informação seria uma possível falta de uniformidade para um polo de focalização capaz de detectar e efetuar esta possível diferença e, em efetuando-a, constituir-se e realizar-se como organização neguentrópica e autopoiética (MORIN, 2008, p. 369-372).

\section{A crítica ao argumento de Floridi}

Apesar de pretender situar sua filosofia da informação num âmbito mais metafísico do que estritamente epistemológico, Floridi afirma que a noção central ou nuclear da filosofia da informação é a noção de informação factual, que ele identifica à informação "epistemicamente orientada" (FLORIDI, 2010, p. 41). De acordo com ele, "para entender o que é informação, a melhor coisa a fazer é começar analisando-a em termos do conhecimento que ela pode propiciar sobre sua referência" (FLORIDI, 2010, p. 41). Ora, esse tipo de afirmação parece contrariar a ideia de que a filosofia da informação é logicamente anterior à teoria filosófica do conhecimento.

Uma maneira de tentar dissipar essa aparência de contradição seria a seguinte. Suponhamos que a filosofia da informação deva ser compreendida como uma teoria geral da realidade, uma teoria que, por estar mais preocupada com a especulação sobre os princípios fundamentais do que com a identificação de correlações empiricamente verificáveis, pode ser qualificada como metafísica. Compreendida nesse sentido, a filosofia da informação exige alto grau de familiaridade com conhecimentos científicos especializados, no mínimo conhecimentos físicos e biológicos. E, embora 
o caminho seja incrivelmente longo e sinuoso, talvez seja possível passar desta teoria geral da realidade para uma teoria geral do conhecimento humano, definida num enfoque naturalista ou cientificista, que prescinde das noções irredutivelmente epistêmicas próprias da teoria filosófica do conhecimento, como compreensão de condições de verdade ou validação e competência no manejo de tais condições, equivalendo à competência no uso de razões para crer. Ter-se-ia então um tipo de semântica naturalizada, que substitui processos irredutivelmente epistêmicos por processos informacionais estritamente naturais. Entre os filósofos, uma das tentativas mais famosas de realização desta proposta é o livro que Fred Dretske publica em 1981, Knowledge and the flow of information. E a proposta certamente pode ser relacionada aos princípios gerais da psicologia cognitiva e da ciência cognitiva em geral.

Essa espécie de proposta suscita uma série de questionamentos. Entretanto, para os propósitos de nossa argumentação, mais importante do que esses questionamentos é o fato de que o próprio Floridi estabelece uma distinção entre, de um lado, a "informação ambiental" enfocada por Dretske, e, de outro lado, a "informação semântica" (conteúdo semântico, dado com significado) por ele analisada. De acordo com ele, "plantas, animais e mecanismos são certamente capazes de fazer uso prático de informação ambiental, mesmo na ausência de qualquer (processamento semântico de) dado com significado" (FLORIDI, 2005, p.13)3. No contexto desse tipo de afirmação, "processamento semântico de dados com significado" parece constituir um processo irredutivelmente epistêmico, centrado em compreensão e uso competente de condições de verdade ou validação, equivalentes a razões para crer.

Além disso, se lembrarmos da tese de Floridi de que a biblioteconomia deve ser vistas como filosofia da informação aplicada, o seguinte argumento se impõe. Embora as informações com que lida a biblioteconomia sejam dos mais variados tipos e formas, algumas delas certamente se situam no plano das realizações mais elaboradas e sofisticadas

\footnotetext{
${ }^{3}$ Floridi afirma explicitamente que o artigo a que estamos nos referindo é baseado em trabalho de 2003 mencionado no artigo de 2004.
} 
das faculdades de conhecimento do homem, como teorias científicas e obras de arte. Ora, se a semântica naturalizada de Dretske exibe algum grau de plausibilidade no nível das realizações mais elementares das faculdades de conhecimento, como a percepção e os juízos de percepção, quando passamos deste nível para o nível das realizações mais sofisticadas ela perde quase toda plausibilidade, pelo menos no atual estágio da ciência cognitiva. No nível das manifestações mais elaboradas do conhecimento humano, as obras parecem encarnar processos irredutivelmente epistêmicos, como compreensões e ações baseadas em razões (razões em sentido amplo, incluindo as razões ou intuições envolvidas nos atos de criação artística). Isso significa que, para corresponder ao objetivo de qualificar-se como fundamento conceitual da biblioteconomia, um objetivo que o próprio Floridi em princípio assume, a filosofia da informação precisa desenvolver análises de caráter irredutivelmente epistêmico, ou seja, precisa ser, antes de tudo, uma teoria filosófica do conhecimento, embora possa ser mais do que isso. Parece ser equivocada a tentativa de apresentá-la como logicamente anterior à teoria filosófica do conhecimento, na medida em que essa tentativa sugere um indesejável esvaziamento do âmbito de análise irredutivelmente epistêmico.

Suponhamos então que a filosofia da informação visada por Floridi deva ser situada no quadro da epistemologia. Ora, a teoria filosófica do conhecimento, quer nas abordagens realistas ou objetivistas, quer nas abordagens construtivistas ou pragmáticas, de fato apresenta um caráter prescritivo, como afirma Floridi. Trata-se sempre de determinar as condições que devem ser seguidas nos processos de justificação ou legitimação envolvidos nas práticas epistêmicas, em geral. Entretanto, se pensarmos no modelo habermasiano de epistemologia construtivista, torna-se possível afirmar que, neste modelo, o prescritivismo epistemológico se manifesta de forma apenas indireta, ou mediada. Isto ocorre porque, neste modelo, como veremos mais à frente, as condições de justificação não são apresentadas em termos de correspondência à realidade objetiva, mas de promoção refletida e consciente dos interesses de conhecimento em cada caso fundamentais. A hipótese que tentaremos defender é a seguinte. Ao contrário do que ocorre com o prescritivismo típico das abordagens objetivistas, o prescritivismo 
indireto da epistemologia habermasiana é perfeitamente compatível com as necessidades e valores próprios da biblioteconomia e museologia; mais precisamente, ele lhes confere plena legitimidade no variado terreno dos conhecimentos e práticas humanos.

Sem atentar para a distinção entre epistemologias objetivistas e epistemologias construtivistas, Floridi recorre a uma famosa passagem de Hume para demonstrar a incompatibilidade entre o caráter essencialmente prescritivo da teoria do conhecimento e, de outro lado, as necessidades e valores próprios da biblioteconomia (FLORIDI, 2002, p. 40-41). Numa passagem da sua Investigação sobre o entendimento humano (1748), Hume aplica as condições de verdade defendidas em sua própria epistemologia aos livros de metafísica e teologia escolásticas que enchiam as bibliotecas de seu tempo. Convencido de que tais livros não satisfariam nenhuma das duas espécies de condições de verdade admitidas em sua epistemologia (condições de coerência lógico-formal, típicas do conhecimento matemático, e condições de verificação empírica, típicas do conhecimento sobre questões de fato e existência), Hume conclui que eles só contêm sofismas e ilusões, e recomenda que sejam pura e simplesmente queimados. Floridi menciona o horror que esta recomendação corretamente despertaria em qualquer bibliotecário como um sinal da incompatibilidade entre a teoria filosófica do conhecimento, com seu caráter epistemologicamente prescritivo, e, por outro lado, as necessidades e valores próprios da biblioteconomia.

Floridi concebe o prescritivismo da teoria do conhecimento de um modo uniforme, e o ilustra com a teoria humeana do conhecimento. Diante disso, nosso argumento é o seguinte. Para os propósitos de nossa argumentação, a epistemologia de Hume pode ser considerada como exemplo de uma abordagem grosso modo realista do conhecimento e da verdade, na qual o objeto do conhecimento é concebido como uma realidade independente das ideias em geral dos sujeitos, incluindo interesses e valores. Mais precisamente, o objeto do conhecimento é concebido em termos de entidades e processos estritamente naturais, essencialmente independentes das ideias como manifestações da reflexividade e crítica dos sujeitos. Como o objeto do conhecimento é independente das ideias, 
interesses e valores dos sujeitos do conhecimento, o conhecimento do objeto deve ser igualmente independente destes elementos "subjetivos". Não se considera a tese de que a relação com o objeto seja mediada por interesses e valores dos sujeitos do conhecimento; em outras palavras, não se considera a tese de que a validade dos conhecimentos - ou das informações - dependa dos interesses dos sujeitos, estando, portanto, essencialmente associada a um modo de encaminhar, interpretar e usar tais informações e conhecimentos.

Deste ponto de vista, o ideal do conhecimento é corresponder à realidade independente, ou, ao menos, corresponder à objetividade da realidade independente, concebida em termos de identidade, uniformidade e regularidade, ou seja, qualidades que fazem com que a realidade objetiva seja essencialmente a mesma para todos os sujeitos que procuram conhecê-la. Nas versões contemporâneas da abordagem grosso modo realista, admite-se que não temos como sair de nossa visão e linguagem para comparar nossos enunciados e teorias com a realidade em si mesma, ou seja, para verificar até que ponto eles correspondem a tal realidade. Por isso, as condições da verdade passam a ser definidas em termos de observações que, ainda que sejam linguisticamente mediadas, são iguais para todos os sujeitos: observações em relação às quais não há qualquer diferença ou desacordo entre os sujeitos competentes na prática observacional e linguística envolvida no conhecimento da realidade objetiva.

Nesta abordagem, o caráter epistemologicamente prescritivo da teoria filosófica do conhecimento vincula-se à noção de verdade como correspondência à objetividade do objeto, concebida em termos de observações que bloqueiam quaisquer diferenças na esfera dos sujeitos, quer diferenças na interpretação, quer no encaminhamento e uso destas observações e das crenças nelas baseadas. Nesta abordagem, prioriza-se um uso único e fundamental das observações, informações e conhecimentos em geral: descrição e explicação da realidade objetiva. Daí se origina a prescrição de rejeitar como inválidas todas as crenças e teorias que não sejam devidamente verificadas ou corroboradas por observações bloqueadoras de qualquer desacordo entre os sujeitos observacional e linguisticamente 
competentes. À unicidade da noção de verdade corresponde a unicidade da noção de falsidade: crenças e teorias que não sejam apoiadas por observações capazes de extorquir um acordo dos sujeitos cientificamente competentes são pura e simplesmente falsas, não servem para nada, não são suscetíveis de qualquer encaminhamento ou uso cientificamente válido. Sendo assim, podem até ser condenadas às chamas, como ousadamente propõe Hume.

Cabe destacar, entretanto, que não é preciso sair da abordagem grosso modo objetivista para rejeitar a queima proposta por Hume. Floridi parece não se dar conta de que o prescritivismo cientificista forte típico desta abordagem é compatível com uma concepção positivista da biblioteca e do museu, como locais de acesso a "meras curiosidades". Nesta concepção, as fontes de informação armazenadas em bibliotecas e museus só têm papel num tipo de conhecimento radicalmente distinto do conhecimento científico e objetivo, a saber, o conhecimento da história das ideias, ou das curiosas ideias produzidas pela inventividade humana. Deste ponto de vista, é possível afirmar que, ainda que se trate de um conhecimento nitidamente inferior ao conhecimento científico propriamente dito, é um conhecimento que tem seu lugar na vida da sociedade, nem que seja nos momentos de lazer e diversão aos domingos e feriados... Ora, a nosso ver, o horror do bibliotecário diante da sugestão de queimar livros "ultrapassados" vai (ou deve ir) muito além desse apego às divertidas curiosidades do passado.

\section{O modelo habermasiano de epistemologia construtivista}

A partir de agora, tentaremos desenvolver a hipótese de que a epistemologia social de Habermas propicia uma boa fundamentação teórica para biblioteconomia e museologia, permitindo superar os limites do prescritivismo epistemológico forte típico das abordagens positivistas do conhecimento científico. Antes de dar início à argumentação propriamente dita, cabe fazer uma observação preliminar. A obra de Habermas é extraordinariamente vasta, diversificada e nuançada, e não seria possível apresentar nossa hipótese sob a forma de um comentário detalhado e textualmente fundamentado do desenvolvimento da obra como um todo. Só podemos apresentá-la sob a forma de uma proposta interpretativa 
geral e abrangente, que visa integrar a crítica à abordagem positivista do conhecimento a certos tópicos fundamentais da teoria da sociedade de Habermas.

Começaremos com um esclarecimento da especificidade da teoria do conhecimento de Habermas no quadro geral da epistemologia póspositivista. Aproveitando os termos empregados por Floridi, pode-se afirmar que a abordagem revolucionária da epistemologia social define-se por duas características fundamentais. Há em primeiro lugar a afirmação genérica de que conhecimento, verdade e justificação são "construções sociais". Em segundo lugar, trata-se de uma abordagem de caráter normativo, o que significa que a noção de construção social não pode ser reduzida à tese de que conhecimento e verdade são expressões de sistemas de poder que impõem aquilo que é socialmente aceito e transmitido como verdadeiro em determinada época. Longe de indicar imposição de um regime de verdade segundo condições sociopolíticas facticamente vigentes, a noção normativa de construção social da verdade aponta para o fato de que a justificação racional de hipóteses e teorias baseia-se em acordos interpretativos entre os participantes da prática de pesquisa, em vez de se basear, como pensam os teóricos positivistas, em observações "objetivas", ou seja, observações ingenuamente tomadas como evidências que falam por si mesmas e que são absolutamente cogentes, ou como evidências que bloqueiam qualquer possibilidade de desacordo entre os sujeitos à medida mesmo que estão depuradas de qualquer componente interpretativo de caráter subjetivo, intersubjetivo, cultural ou histórico.

Assim, situada numa abordagem de caráter normativo, a noção de construção social não pode ser reduzida à afirmação de que o sistema social, tomado como sistema de poder, constrói a verdade sem nenhuma consideração pelos dados disponíveis, sem ser minimamente limitado pelos dados. Trata-se antes de afirmar que a verdade equivale a um acordo intersubjetivo a respeito da interpretação e ponderação que devem ser conferidas às observações disponíveis, um acordo idealmente orientado pelos critérios e valores constitutivos da busca cooperativa da verdade - embora a análise e denúncia da influência de interesses e condições de poder político-social sejam não só compatíveis como aproveitadas e assumidas pelas abordagens normativas de caráter crítico. De qualquer modo, no âmbito das questões mais estritamente epistemológicas, se a 
epistemologia pós-positivista, por um lado, rejeita a tese de observações que falam por si mesmas, ela, por outro lado, sustenta que a interpretação e ponderação que devem lhes ser conferidas são condicionadas por interesses e valores de caráter comum, constitutivos de um empreendimento comum e compartilhado. A tese básica é aqui a seguinte: mesmo que o objeto seja constituído por uma realidade independente das ideias, valores e interesses humanos, a relação com esse objeto é mediada por interesses, e pelos critérios nos quais eles se exprimem. Um dos grandes expoentes da epistemologia pós-positivista, Thomas Kuhn menciona os seguintes valores: "exatidão nas predições, número de problemas resolvidos, coerência teórica, simplicidade ou elegância" (KUHN, 2000, p. 229-252).

A grande contribuição da obra habermasiana à epistemologia construtivista consiste numa reflexão que distingue diversos tipos de interesses de conhecimento e, correspondentemente, diversos tipos de validade ou legitimidade das propostas de conhecimento, além da verdade em sentido estrito, que é a forma de validade típica das propostas de conhecimento produzidas no âmbito das ciências da natureza. Para Habermas, à prática das ciências da natureza subjaz um interesse técnico, que é um interesse na eficiência e êxito na lida com uma realidade que nos é independente, que não está ao nosso inteiro dispor (HABERMAS, 1971; 2004, cap. 5). O interesse técnico implica interesse no maior grau possível de previsão e controle da realidade independente que, por sua vez, implica interesse não só em regras e correlações de caráter geral, que ditam um caráter nomológico às propostas de conhecimento, mas também em mecanismos de intervenção no funcionamento de uma realidade em princípio alheia à racionalidade e à reflexividade intersubjetivamente exercidas.

Além das ciências da natureza, também as ciências sociais "sistemáticas" têm o objetivo de produzir conhecimento de tipo nomológico (HABERMAS, 1971, p. 310; McCARTHY, 1981, p. 58) ${ }^{4}$. Embora seu objeto não seja a natureza, mas processos sociais, as ciências sociais

\footnotetext{
${ }^{4}$ A referência está sendo feita à edição norte americana do livro Conhecimento e interesse, que inclui como apêndice um texto originalmente publicado em Merkur em 1965, também intitulado Conhecimento e interesse. A página citada pertence a este apêndice. O texto publicado em Merkur foi incluído por Habermas na obra Técnica e ciência como "Ideologia", publicado na Alemanha no mesmo ano do livro Conhecimento e interesse, 1968.
} 
sistemáticas abordam tais processos num enfoque objetivador, como processos objetivados, ou seja, alheios às interações comunicativas entre sujeitos, interações baseadas na compreensão, aceitação e cumprimento de razões. Pode-se afirmar que, à semelhança das ciências da natureza, elas estão fundadas no interesse técnico na eficiência e sucesso na lida com processos objetivados. A orientação nomológica equivale, neste caso, a uma orientação para descrições, modelos e análises de caráter quantitativo, interessadas na identificação de correlações universalmente vigentes entre variáveis quantificadas.

Pode-se tentar situar as ciências fundadas no interesse técnico no quadro da teoria da sociedade elaborada em Teoria da ação comunicativa. Desse ponto de vista, tanto as ciências da natureza quanto as ciências sociais sistemáticas pertencem à dimensão sistêmica da sociedade, que emerge a partir do aumento de complexidade das tarefas produtivas e organizacionais implicadas na reprodução material da existência social. Com o brutal aumento de complexidade, tais tarefas assumem a feição de funções sistêmicas, ou seja, processos de encadeamento de operações que não aceitam as limitações quanto ao alcance e rapidez típicas dos meios comunicativos de coordenação das ações, baseados na compreensão, aceitação e eventual questionamento de razões, no domínio da racionalidade intersubjetivamente constituída e exercida. Com efeito, o aumento da complexidade social acarreta não apenas um aumento na quantidade e variedade dos dados que precisam ser considerados e processados para a execução das tarefas de reprodução material, mas também a necessidade de um processamento comparativamente rápido e seguro destes dados e das decisões e operações a eles vinculadas, um processamento que seja relativamente imune às interrupções e questionamentos típicos dos meios comunicativos de coordenação social.

É por isso que, ao contrário do que ocorre nos processos de trabalho desenvolvidos em sociedades pouco complexas, que se realizam por meio de uma prática linguística sediada no domínio da intersubjetividade (McCARTHY, 1981, p.16-30), as tarefas produtivas e organizacionais implicadas na reprodução material de sociedades complexas colocam exigências que já não podem ser atendidas pelos meios de coordenação constituídos pelas ações comunicativas. $\mathrm{O}$ aumento da complexidade 
social transforma os processos de trabalho em funções produtivas e organizacionais descoladas do mundo da vida e estruturadas como sistema. Em outras palavras, enquanto nas sociedades pouco complexas "trabalho" e "interação social" constituem duas dimensões da prática linguística constitutiva do mundo da vida como domínio da racionalidade intersubjetivamente vivenciada e exercida, no caso das sociedades complexas a estruturação sistêmica do trabalho descola-o do terreno da intersubjetividade, isolando-o como domínio de uma racionalidade técnica impermeável às razões como elementos intersubjetivamente compreensíveis, aceitáveis e criticáveis.

Na esfera do trabalho de sociedades pouco complexas, os atos de fala de tipo constatativo, equivalentes a ações comunicativas desenvolvidas no modo cognitivo da comunicação, têm certa prioridade na prática linguística por meio da qual se realizam as tarefas da reprodução material. Mas nessas sociedades, como dito acima, as ações comunicativas de tipo cognitivo situam-se no âmbito do mundo da vida, um âmbito no qual os atos de fala constatativos encontram-se inextricavelmente entretecidos a atos de fala de tipo regulativo, ligados aos valores e normas intersubjetivamente aceitos e vivenciados (HABERMAS, 1989). É exatamente esse entrelaçamento com valores e normas intersubjetivamente vivenciados que confere um caráter substantivo às razões implicadas nas ações comunicativas de tipo cognitivo. Em outras palavras, é este entrelaçamento que permite que se fale de razões propriamente ditas, elementos vinculados à competência de compreender, questionar, aceitar e vivenciar o sentido do que está sendo dito e feito, uma competência típica dos sujeitos e do domínio da intersubjetividade.

Nas sociedades complexas, por outro lado, as tarefas implicadas na reprodução material já não cabem no horizonte do mundo da vida. A esfera da reprodução material desvincula-se do domínio da intersubjetividade e estrutura-se como sistema. A racionalidade envolvida na organização e encadeamento das tarefas da reprodução material deixa de direcionar-se para o sentido encarnado em pretensões de validade intersubjetivamente compreensíveis e criticáveis, e passa a expressar-se em fórmulas, modelos, códigos e programas de caráter puramente formal ou técnico, que permitem processamento e encadeamento rápidos, eficientes e de longo alcance da 
enorme quantidade e variedade de dados, decisões e operações implicados na execução das funções de reprodução material da sociedade. Do ponto de vista histórico, o aumento da complexidade social manifesta-se na emergência e desenvolvimento das organizações burocráticas do Estado, cujo ingrediente fundamental é a estatística. Os dados estatisticamente modelados e utilizados constituem a "informação" como componente fundamental dos processos sistêmicos de reprodução material (VREEKEN, 2005). Começam a emergir os sistemas de gestão da informação, para cujo desenvolvimento as tecnologias da comunicação e da informação desempenharão posteriormente papel fundamental.

Diferentemente dos atos de fala produzidos no terreno da racionalidade intersubjetivamente exercida, as instruções sistêmicas, por serem geradas e transmitidas segundo códigos e programas tecnicamente embasados, constituem um mecanismo de coordenação social impermeável à crítica vinculada à reflexão sobre valores e fins de caráter substantivo. Em certa medida, ou até um certo limite, essa impermeabilidade é positiva: como dito acima, o aumento da complexidade social traz consigo a necessidade de minorar e até mesmo abafar interrupções oriundas de questionamentos deslocados e nesse sentido impertinentes. Nesse sentido, os recursos sistêmicos de organização da vida social são inevitáveis e até bem-vindos. Mas Habermas vê no sistema não apenas uma dimensão inevitável da existência social, mas também uma "patologia" das sociedades contemporâneas, equivalendo à autonomização e reificação de mecanismos de coordenação social que deveriam ser consciente e criticamente usados pelos sujeitos linguisticamente constituídos (HABERMAS, 1991, p. 250260). O modo de pensar sistêmico, expressão da racionalidade meramente formal ou técnica, autonomiza-se em relação à competência dos sujeitos de compreender, vivenciar, discutir e seguir razões propriamente ditas, ou seja, razões que apresentam um caráter substantivo, propiciado pelo entrelaçamento com normas e valores intersubjetivamente compreendidos e aceitos. Na verdade, ao autonomizar-se em relação à racionalidade intersubjetivamente exercida, o modo de pensar sistêmico extrapola o âmbito da organização da reprodução material e conquista terreno na esfera da intersubjetividade, minando a possibilidade de se vivenciar as 
relações e interações sociais como um empreendimento fundado em razões substantivas comuns e compartilhadas.

A colonização do domínio da intersubjetividade pelo modo de pensar sistêmico apresenta três características básicas. Em primeiro lugar, um enfoque objetivador dos seres humanos: no modo de pensar sistêmico, os seres humanos são enfocados sob a perspectiva do observador, ou seja, são tratados, não como sujeitos capazes de compreender e seguir razões propriamente ditas, mas como itens objetivos, a serem geridos segundo programas técnicos, ou até manipulados por informações estrategicamente difundidas. Em segundo lugar, há uma privatização dos valores e fins em geral, equivalendo a um esvaziamento da possibilidade de interesses e fins comuns, ou seja, aceitos como bons para todos os participantes do empreendimento social. A noção do valioso é restringida a interesses e fins admitidamente privados, que colocam todas as expressões de caráter regulativo (proferimentos reguladores das ações dos seres humanos) no quadro da alternativa excludente "ou é bom para outro(s) ou é bom para mim”. Neste contexto, as decisões individuais são tomadas por cálculos de utilidade fundados na noção do "bom para mim". E um observador tecnicamente inteligente, munido do conhecimento dos itens objetivados já dados e dos instrumentos de introdução de novos itens deste tipo (informações referidas a possíveis recompensas e/ou perdas), torna-se capaz de prever e manipular as consequências que resultam deste tipo de tomada de decisão. Além disso, se no nível micro das interações individuais o "sistema" não pode prescindir completamente de ações comunicativas, no contexto da privatização sistêmica das razões para agir predomina a forma "fraca" de ação comunicativa, que corrobora o esvaziamento do caráter comum do empreendimento social. "Nas formas 'fracas' do uso comunicativo da linguagem e do agir comunicativo, a racionalidade comunicativa entrelaça-se com a racionalidade teleológica de agentes orientados pelo sucesso" (HABERMAS, 2004, p.121).

A terceira característica da expansão desmedida do sistema já foi mencionada acima. Trata-se da tendência à autonomização e reificação do modo de pensar sistêmico, incluindo tanto o enfoque objetivador quanto a perspectiva privatista. De um ponto de vista analítico, é possível distinguir dois aspectos do sistema. Sob o primeiro aspecto, o sistema designa uma 
estrutura de pensamento e ação que ainda está referida a sujeitos; sob este aspecto, em outras palavras, o sistema ainda é permeável às competências típicas de sujeitos linguisticamente constituídos, incluindo a competência de distanciar-se reflexiva e criticamente do modo de operar funcionalmente eficaz, de demorar-se nessa distância e com isso estabelecer os limites do terreno em que ele legitimamente se exerce. Entretanto, à medida que o valor da eficiência operacional se expande, os sujeitos se entregam e alienam no enfoque objetivador do próprio sujeito, que mina a competência de demorar-se na reflexão produtora da vivência de sentido, ou de razões propriamente ditas, que sempre têm um caráter substantivo. E com isso emerge o segundo aspecto do sistema, sob o qual o termo designa uma estrutura operacional na qual a competência da racionalidade distancia-se cada vez mais da compreensão, discussão e vivência de razões substantivas e do sentido a elas equivalente, para restringir-se à capacidade de seguir instruções e programas de caráter meramente técnico. A estruturação sistêmica da vida social passa a basear-se cada vez mais em meios tecnológicos que enredam os indivíduos na fascinação de mensagens midiáticas que massageiam os códigos e programas simplesmente dados. $\mathrm{O}$ consumo rápido e fácil de mensagens aduladoras abafa a capacidade de demorar-se na reflexão produtora de distanciamento crítico.

Diante deste diagnóstico do tempo presente, ganham corpo interesses de conhecimento voltados para a preservação do domínio da intersubjetividade e para a superação da tendência à autonomização e reificação do modo de pensar próprio da dimensão sistêmica das sociedades complexas. Trata-se de superar a tendência ao enrijecimento, congelamento e autorreprodução automática das regularidades sociais que foram produzidas pelo próprio modo de agir sistêmico. As propostas de conhecimento sustentadas por estes interesses possuem um tipo de legitimidade epistêmica distinto da verdade em sentido estrito. Do ponto de vista da obra habermasiana como um todo, a verdade pode ser definida como o tipo de legitimidade que cabe às propostas de conhecimento orientadas para a promoção do interesse técnico na eficiência e sucesso na execução das funções sistêmicas implicadas na reprodução material das sociedades complexas. Ela só é cabível para formas de conhecimento relacionadas a processos objetivos ou objetivados. Propostas de conhecimento orientadas 
para a preservação e revigoramento do domínio da intersubjetividade têm uma forma distinta de legitimidade epistêmica. Pode-se propor o termo "reflexionante" (que suscita e promove uma atitude reflexiva) para designar a qualidade e legitimidade epistêmicas destas propostas de conhecimento.

Independentemente do termo, cabe destacar as qualidades que dão legitimidade epistêmica e social às propostas de conhecimento voltadas para o revigoramento do domínio da intersubjetividade. Tais propostas iluminam perspectivas de vida diferentes; elas discutem aspectos válidos e inválidos de formas de vida diferentes; elas promovem a abertura ao outro, ou seja, a disponibilidade para uma consideração razoável das demandas e perspectivas valorativas de outros sujeitos; elas analisam e alimentam a competência dos sujeitos de compreender, discutir, formular e reformular razões para agir de caráter substantivo. Em suma, elas abrem espaço para a construção discursiva de valores e normas comuns, aceitáveis por todos os participantes do empreendimento social.

Em 1968, em Conhecimento e interesse, propostas de conhecimento desta espécie são situadas por Habermas em dois campos científicos distintos do campo das ciências "empírico-analíticas": o campo das ciências "histórico-hermenêuticas" e o das ciências "criticamente orientadas". Esta preocupação com a classificação das ciências foi deixada de lado quando a orientação crítica da reflexão habermasiana passou a incidir mais na tentativa de inserir o conceito de ação comunicativa no quadro da tradição da teoria sociológica em sentido estrito. Talvez seja possível afirmar que esta mudança tem a ver com a percepção de que o interesse crítico não deve ser localizado no quadro da prática científica, mas no quadro de uma prática social mais abrangente, enraizada nas estruturas linguístico-comunicativas da integração social em geral. Mesmo que essa afirmação seja plausível, isso não invalida o sentido e validade do conceito de um interesse de conhecimento de caráter prático e crítico, voltado para a preservação e revigoramento do domínio da intersubjetividade, contra a reificação do modo de agir sistêmico em regularidades sociais pretensamente objetivas. Práticas científicas e paracientíficas (como as desenvolvidas em bibliotecas e museus) sustentadas por este interesse (prático e crítico) estão estreitamente associadas às práticas comunicativas e discursivas desenvolvidas nas diferentes esferas da racionalidade 
intersubjetivamente exercida: mundo da vida, esfera pública e canais institucionais da construção discursiva das normas de ação comuns.

No quadro teórico habermasiano, talvez seja plausível afirmar que a "informação", o objeto da ciência da informação, pode ser tomada em dois sentidos. Em primeiro lugar, como nutriente dos processos sistêmicos inevitavelmente envolvidos na organização tecnicamente eficiente das funções de reprodução material das sociedades complexas. Aqui seria o espaço da "gestão da informação". Uma gestão da informação criticamente consciente dos limites da racionalidade meramente sistêmica mereceria o título de "gestão pública da informação", necessariamente comprometida com a transparência das estruturas sistêmicas para os sujeitos que devem saber enquadrá-las no domínio da racionalidade intersubjetivamente exercida. Em segundo lugar, a informação pode ser tomada como nutriente dos processos comunicativos envolvidos no revigoramento do domínio da intersubjetividade, que equivale a um atravessamento do sistema por práticas vinculadas à racionalidade intersubjetivamente exercida. Práticas informacionais centradas na agilização e ampliação do acesso aos mais variados tipos de dados podem ser retratadas como processos de mediação - não só mediação entre sujeitos, grupos e comunidades linguisticamente constituídos, mas também, indiretamente, entre os sujeitos em geral e, de outro lado, estruturas sistêmicas. Na sua feição mediadora, tomada como dado que, ainda que distante ou raro, torna-se rápida e facilmente acessível por sujeitos capazes de incorporá-lo numa vivência de sentido, a informação é elemento que, ao introduzir no sistema a cunha da intersubjetividade, força-o a abrir-se para as expressões da racionalidade intersubjetivamente exercida. Bibliotecas, mediatecas e museus podem ser pensados como instituições centradas nesses processos informacionais de caráter mediador.

Se estas considerações forem procedentes, elas demonstram que a epistemologia social habermasiana supera o prescritivismo epistemológico forte típico das abordagens objetivistas do conhecimento. Propostas de conhecimento fundadas em interesses de caráter prático e crítico não possuem uma forma "veritativa" de legitimidade epistêmica, mas uma forma "reflexionante". No contexto da forma veritativa de validade epistêmica, o 
prescritivismo epistemológico inerente à teoria filosófica do conhecimento manifesta-se sob a forma de uma determinação dos conteúdos epistêmicos em que devemos acreditar. No contexto da forma reflexionante, em contrapartida, ele se manifesta sob a forma da determinação da atitude epistêmica que devemos adotar e promover - uma atitude de abertura e inclusão do outro. E esta manifestação do prescritivismo epistemológico explica o lugar e o valor das práticas epistêmicas, paracientíficas e sociais desenvolvidas na esfera da biblioteconomia e museologia.

\section{Referências}

FLORIDI, Luciano. On defining library and information science as applied philosophy of information. Social epistemology, Londres, v. 16, n. 1, p. 37-49, Jan. 2002.

. Information. In: FLORIDI, L. (Ed.). The blackwell guide to the philosophy of computing and information. Oxford: Blackwell, 2003. p.4061.

. Biblioteconomia e ciência da informação (BCI) como filosofia da informação aplicada: uma reavaliação. Tradução de Solange Puntel Mostafa e Denise Viuniski da Nova Cruz. InCID: R. Ci. Inf. e Doc., Ribeirão Preto, v. 1, n. 2, p. 37-47, 2010.

. Semantic conceptions of information. Stanford encyclopedia of philosophy. 2005. Disponível em: <http://plato.stanford.edu/entries/ information-semantic/>. Acesso em: 10 Jan. 2012.

GOLDMAN, Alvin. Social epistemology. Stanford encyclopedia of philosophy. 2006 Disponível em: <http://plato.stanford.edu/entries/ epistemology-social> . Acesso em: 20 Jan. 2012.

HABERMAS, Jürgen. Knowledge and human interests. Tradução de Jeremy Shapiro. Boston: Beacon Press, 1971.

. ?Qué significa pragmática universal? In. . Teoría de la acción comunicativa: complementos y estudios previos. Tradução de Manuel Jiménez Redondo. Madrid: Cátedra, 1989. p. 299-368.

. A Reply. In: HONNETH, A.; JOAS, H. (Ed.). Communicative 
action: Essays on Jürgen Habermas's 'The theory of communicative action'. Tradução de Jeremy Gaines e Doris Jones. Massachusetts: MIT Press, 1991. p. 214-264.

. Verdade e justificação. Tradução de Milton Camargo Mota. São Paulo: Loyola, 2004.

KUHN, Thomas. A estrutura das revoluções cientificas. Tradução de Beatriz Vianna Boeira e Nelson Boeira. São Paulo: Perspectiva, 2000.

McCARTHY, Thomas. The critical theory of Jürgen Habermas. Massachusetts: MIT Press, 1981

MORIN, Edgar. O método - A natureza da natureza. Tradução de Ilana Heineberg. Porto Alegre: Sulina, 2008.

VREEKEN, Arjan. The history of information: lessons for information management. Sprouts: working papers on information systems, v. 5, n. 2. 2005. Disponível em: <http://sprouts.aisnet.org/5-2>. Acesso em: 30 Jan. 2012.

Data de registro:05/06/2012

Data de aceite:31/10/2012 